\title{
Parkinson's Disease: Biomarkers, Treatment, and Risk Factors
}

\author{
Fatemeh N. Emamzadeh ${ }^{1}$ and Andrei Surguchov ${ }^{2 *}$ \\ ${ }^{1}$ Division of Biomedical and Life Sciences, Faculty of Health and Medicine, University of Lancaster, Lancaster, \\ United Kingdom, ${ }^{2}$ Department of Neurology, Kansas University Medical Center, Kansas City, KS, United States
}

Parkinson's disease (PD) is a progressive neurodegenerative disorder caused mainly by lack of dopamine in the brain. Dopamine is a neurotransmitter involved in movement, motivation, memory, and other functions; its level is decreased in PD brain as a result of dopaminergic cell death. Dopamine loss in PD brain is a cause of motor deficiency and, possibly, a reason of the cognitive deficit observed in some PD patients. PD is mostly not recognized in its early stage because of a long latency between the first damage to dopaminergic cells and the onset of clinical symptoms. Therefore, it is very important to find reliable molecular biomarkers that can distinguish PD from other conditions, monitor its progression, or give an indication of a positive response to a therapeutic intervention. PD biomarkers can be subdivided into four main types: clinical, imaging, biochemical, and genetic. For a long time protein biomarkers, dopamine metabolites, amino acids, etc. in blood, serum, cerebrospinal liquid (CSF) were considered the most promising. Among the candidate biomarkers that have been tested, various forms of $\alpha$-synuclein ( $\alpha$-syn), i.e., soluble, aggregated, post-translationally modified, etc. were considered potentially the most efficient. However, the encouraging recent results suggest that microRNA-based analysis may bring considerable progress, especially if it is combined with $\alpha$-syn data. Another promising analysis is the advanced metabolite profiling of body fluids, called "metabolomics" which may uncover metabolic fingerprints specific for various stages of PD. Conventional pharmacological treatment of PD is based on the replacement of dopamine using dopamine precursors (levodopa, L-DOPA, L-3,4 dihydroxyphenylalanine), dopamine agonists (amantadine, apomorphine) and MAO$B$ inhibitors (selegiline, rasagiline), which can be used alone or in combination with each other. Potential risk factors include environmental toxins, drugs, pesticides, brain microtrauma, focal cerebrovascular damage, and genomic defects. This review covers molecules that might act as the biomarkers of PD. Then, PD risk factors (including genetics and non-genetic factors) and PD treatment options are discussed.

\section{Keywords: Parkinson's disease, biomarkers, $\alpha$-synuclein, microRNAs, orexin}

\begin{abstract}
Abbreviations: 8-OHdG, 8-hydroxy-2'-deoxyguanosine; BBB, blood-brain barrier; CSF, cerebrospinal fluid; DBS, deep brain stimulation; DLBs, dementia with Lewy bodies; GBA, acid $\beta$-glucocerebrosidase; HDLs, high density lipoproteins; LBs, Lewy bodies; LDLs, low density lipoproteins; L-dopa, levodopa; LRRK2, leucine-rich repeat kinase 2; MAOA, monoamine oxidase A; MAOB, monoamine oxidase B; MAPKs, mitogen-activated protein kinases; MAPT, microtubuleassociated protein tau; MPTP, 1-methyl-4-phenyl-1,2,3,6 tetrahydropyridine; PD, Parkinson's disease; PDD, Parkinson's disease dementia; PEA, $\beta$-phenylethylamine; PINK1, PTEN-induced putative kinase 1; SN, substantia nigra; TBP, TATA box-binding protein; $\mathrm{TH}$, tyrosine hydroxylase; VLDLs, very low density lipoproteins.
\end{abstract}




\section{INTRODUCTION}

Parkinson's disease is the second most common neurodegenerative disease characterized by a progressive loss of dopaminergic neurons in the SN pars compacta. In $\mathrm{PD}$, there is a long latency between the first damage to cells in at-risk nuclei of the nervous system, and the onset of clinical symptoms. The symptoms and signs of PD usually do not develop until $70-80 \%$ of dopaminergic neurons have already been lost (El-Agnaf et al., 2006). Thus, identifying patients in the period between the presumed onset of dopaminergic cell loss and the appearance of clinical parkinsonism may be of major importance for the development of effective neuroprotective treatment strategies (Berendse et al., 2001). Staining of LBs, the pathological hallmark of PD, to identify affected neurons throughout the nervous system, revealed six neuropathological stages of this disease based on the localization of the involved brain regions (Braak et al., 2003). Examination of brain samples from hundreds of PD patients revealed that the pathological process was relatively uniform. The pathology in the first stage begins in the lower medulla oblongata, specifically the dorsal motor nucleus of the vagal nerve, and the anterior olfactory structures. In stage 2, lesions in the dorsal motor nucleus worsen, inclusions develop in the lower raphe nuclei, and Lewy neurites can be observed in the locus ceruleus. In stage three the $\mathrm{SN}$ is affected. In stage four, lesions appear in the cortex, specifically in the temporal mesocortex. In stage five, the pathology appears in the adjoining temporal neocortical fields, while in stage six cortical involvement is clearly seen. Importantly, cognitive status correlates with the neuropathological stage (Braak et al., 2003). It is also essential to find reliable molecular biomarkers that can distinguish PD from other conditions, monitor its progression, or give an indication of a positive response to therapeutic intervention (Siderowf et al., 2018). $\alpha$-Synuclein $(\alpha-S y n)$ aggregates are assumed to be harmful to dopaminergic neurons in the $\mathrm{SN}$, and their formation may trigger the transmission of toxic $\alpha$-syn from affected cells to other adjacent cells, resulting in a cascade of LBs formation and, subsequently, cell death (Angot and Brundin, 2009; Steiner et al., 2018). This promotes further dopaminergic cell loss caused by the spread of pathogenic forms of $\alpha$-syn to neighboring cells (Luk et al., 2012). The transmission of $\alpha$-syn between cells can be a normal pathway. However, in a stress condition, the aggregation of $\alpha$-syn may be initiated within the receiver cells, where pre-aggregated $\alpha$-syn acts as a 'seed' inducing more aggregation of soluble $\alpha$-syn in a 'prion-like' fashion (Bernis et al., 2015). Furthermore, because $\alpha$-syn aggregates are normally cleared by the proteasome system or by the lysosomes, any defect in clearance mechanisms could cause the spread of PD pathology as undigested toxic $\alpha$-syn transmits to other cells. In accordance with this concept lysosomal inhibition enhances the amount of insoluble $\alpha$-syn, leading to the elevated release of exosomes containing toxic $\alpha$-syn (Luk et al., 2012). In healthy neurons unwanted proteins are cleared via an exosome mediated pathway, thus explaining why $\alpha$-syn can be released from neurons in normal conditions, while any cellular or environmental problem that leads to higher $\alpha$-syn secretion can be harmful to neurons and can be transmitted to other adjacent cells. There is a hypothesis that the accumulation of $\alpha$-syn in PD patients begins in the enteric nervous system that is in nerves in the upper gastrointestinal tract (GI). $\alpha$-Syn produced in GI is spread through vagus to the brain, suggesting a significant role of gut-brain axis in PD development (Liddle, 2018). Therefore, monitoring PD occurrence, diagnosis of early stage of this disease, ability to distinguish it from other parkinsonian syndromes, monitoring of its response to treatment and progression all require the identification of reliable biomarkers. After many years of disease PD can eventually evolve into PDD. The methods of diagnostics and distinctions between PD, PDD, and DLB are described in a recent comprehensive review (McKeith et al., 2017)

\section{NEUROCHEMICAL BIOMARKERS}

\section{Orexin}

Orexin, also known as hypocretin, is a neuropeptide hormone expressed by a small number of neurons of the dorsolateral hypothalamus. Orexin is secreted by the lateral and posterior neurons of the hypothalamus. The hormone regulates many physiological functions, such as the sleep-wake cycle (Hagan et al., 1999), cardiovascular responses, heart rate, and hypertension (Imperatore et al., 2017). PD patients usually suffer from narcolepsy due to the loss of hypocretin neurons in the hypothalamus. The concentration of orexin A is lower in PD patients than in healthy individuals, and the level of orexin is related to the severity of the disease. The more severe is the disease, the higher loss of hypocretin neurons and the lower orexin levels in the CSF are observed (Fronczek et al., 2007). In the late stages of $\mathrm{PD}$, decreased orexin levels may be responsible for daytime sleepiness (Wienecke et al., 2012). In narcolepsy of PD patients elevated levels of glial fibrillary acidic protein (GFAP) in the CSF seem to be causative for the reduction of orexin levels (Takahashi et al., 2015) pointing to GFAP as another potential biomarker. GFAP is an intermediate filament protein of the cytoskeleton that is expressed mostly in astrocytes. Hypophosphorylation and overexpression of GFAP often occur in PD patients, suggesting that these alterations in astrocytes are associated with the pathogenesis of PD (Clairembault et al., 2014). Astrocytes may be involved in the progression of PD by the production of pro-inflammatory cytokines that damage dopaminergic neurons (Rappold and Tieu, 2010). Therefore, PD can be identified by elevated levels of GFAP as an astroglial marker.

\section{8-Hydroxy-2'-Deoxyguanosine}

Reactive oxygen species (ROS) species (such as $\mathrm{O}_{2}-, \mathrm{H}_{2} \mathrm{O}_{2}$, and.OH) can damage biological molecules basically through irreversible reactions causing degenerative processes associated with aging. One of the DNA lesions caused by ROS is an oxidized form of 8-hydroxyguanine (8-OHG) known as 8-OHdG which can be used as a biomarker of DNA damage (Shigenaga et al., 1989). Likewise, an increase in 8-OHdG serum levels has been measured in PD patients compared to the normal individuals. CSF 8-OHdG levels are also higher in PD patients than in 
normal cases, but the difference is not as significant as serum levels. Therefore, $8-\mathrm{OHdG}$ could be developed as a potential biomarker for PD (Kikuchi et al., 2002). It has been shown in the rat model that $\mathrm{PD}$ stage is directly related to urinary $8-\mathrm{OHdG}$ level, suggesting that it can be used as a severity biomarker for PD (Kikuchi et al., 2011). However, it should be remembered that $8-\mathrm{OHdG}$ is a marker of oxidative DNA damage, but not of progression of PD, so its specificity is limited (Simon et al., 2015).

\section{Peripheral Proteasomes and Caspase Activity}

Proteasomes are large protein complexes responsible for degrading and elimination of unwanted and misfolded proteins and therefore are important for cell survival. Damaged proteins that are tagged with ubiquitin molecules by ubiquitin ligase, trigger the ATP-dependent proteolytic activity of the proteasome (Lodish et al., 2004). In PD, the accumulation of proteins within the neurons leads to the formation of pathological intracellular inclusions called LBs. Proteasome dysfunction may be involved in the formation of protein aggregates and associated with LBs (Bentea et al., 2017). In PD mutations disturbing proteasome activity may lead to the accumulation of aggregated $\alpha$-syn (Shadrina et al., 2010; Ciechanover and Kwon, 2015). In some PD cases, mitochondrial deficiency causes the production of more ROS and higher $\alpha$-syn oxidation leading to increased ATP-independent proteasomal activity and higher $\alpha$-syn oligomerization. Depletion of ATP levels in this case inhibits $26 \mathrm{~S}$ proteasome, but $20 \mathrm{~S}$ complex still remains active and degrades oxidized $\alpha$-syn (Martins-Branco et al., 2012). In advanced $\mathrm{PD}$, the severity and duration of PD correlate with reduced proteasome $20 \mathrm{~S}$ activity and increased caspase 3 activity. The activation of caspase and thus initiation of apoptosis is the main reason of proteasome $20 \mathrm{~S}$ activity reduction. Therefore, these proteasome and caspase components may be also considered as potential PD biomarkers (Blandini et al., 2006).

\section{Dopamine, Dopamine Receptor, and Dopamine Transporter Activity}

A catecholamine neurotransmitter dopamine is secreted by the SN, hypothalamus and some other regions of the brain. $\mathrm{TH}$ synthesizes the dopamine precursor (L-DOPA) that is converted to dopamine by L-aromatic amino acid decarboxylase (AADC). In the brain, dopamine is used as the precursor of noradrenaline (norepinephrine) and adrenaline (epinephrine). Loss of dopaminergic neurons in the midbrain and SN of PD brains leads to the reduction of dopamine levels (Obeso et al., 2008). The dopamine transporter (DAT) controls dopamine levels by facilitating its reuptake back to the cytosol. However, free dopamine is toxic for neurons, since its oxidation creates poisonous reactive quinones. Therefore, the vesicular monoamine transporter 2 (VMAT2) stores excess dopamine in vesicles. Thus, any change in dopamine or DAT levels may be an indicator of PD. Moreover, dopamine activates five types of receptors (D1R-D5R) and the severity of PD is related to the decreased expression of the dopamine type 3 receptor (D3R), leading to more severe symptoms because of reduced dopamine signals (Nagai et al., 1996). Therefore, D3R can be also considered as a potential biomarker for PD (Caronti et al., 2001).

Recent studies have point to 3-methoxy-4hydroxyphenylglycol (MHPG) as a valuable biomarker to distinguish several forms of neurodegenerative diseases. This biogenic amine and norepinephrine's metabolite passes the BBB, and analysis of its level in serum and CSF may be helpful to determine cognitive staging in PD, distinguish PD from non-PD controls, DLB versus AD, etc. (Vermeiren and De Deyn, 2017; van der Zee et al., 2018). This method is promising, since the locus coeruleus becomes affected in an earlier stage than the SN by $\alpha$-syn.

In another recent article a preclinical phase of $\mathrm{PD}$ is identified by analysis of dopamine metabolites in CSF. Low CSF concentrations of 3,4-dihydroxyphenylacetic acid (DOPAC) and DOPA identify pre-clinical PD in at-risk healthy individuals (Goldstein et al., 2018).

Catecholamine neurons are not abundant in the nervous system, and their vulnerability in PD and related diseases (Goldstein et al., 2018) is not explained. A concept of autotoxicity assumes intrinsic cytotoxicity of catecholamines in cells in which it is produced. According to a recent theory, PD might develop when 3,4-dihydroxyphenylacetaldehyde (DOPAL) oligomerizes and aggregates $\alpha$-syn, providing a link between synucleinopathy and catecholamine neuron loss in LBD (Goldstein et al., 2018).

According to the "catecholaldehyde hypothesis" for the pathogenesis of PD, long-term increased build-up of DOPAL, the catecholaldehyde metabolite of dopamine, causes or contributes to the eventual death of dopaminergic neurons. LBs, a neuropathological hallmark of PD, contain precipitated $\alpha$-syn. Bases for the tendency of $\alpha$-syn to precipitate in the cytoplasm of catecholaminergic neurons have also been mysterious. Since DOPAL potently oligomerizes and aggregates $\alpha$-syn, the catecholaldehyde hypothesis provides a link between synucleinopathy and catecholamine neuron loss in Lewy body diseases. The concept developed here is that DOPAL and $\alpha$-syn are nodes in a complex nexus of interacting homeostatic systems.

\section{$\alpha$-Synuclein}

$\alpha$-Synuclein, which is found in an aggregated and fibrillar form, has attracted considerable attention as a potential molecular biomarker of PD. (Emamzadeh, 2016). Human $\alpha$-syn is predominantly expressed in the brain in the neocortex, hippocampus, $\mathrm{SN}$, thalamus and cerebellum, and is found in LBs (Surguchov, 2015). It is encoded by the SNCA gene that consists of six exons ranging in size from 42 to 1,110 bp (McLean et al., 2000; Yu et al., 2007). As noted above, the predominant form of $\alpha$-syn is the full-length protein, but other shorter isoforms have been described. Importantly, C-terminal truncation of $\alpha$-syn induces aggregation, suggesting that $\mathrm{C}$-terminal modifications might be involved in the pathology of $\alpha$-syn (Venda et al., 2010). Changes in the levels of $\alpha$-syn have been reported in CSF and plasma of PD patients compared to control individuals (Hong et al., 2010). Recent evidence suggests that $\alpha$-syn can be secreted into the extracellular space of the brain and spread the pathology of PD by propagating in a prion-like fashion (Masuda-Suzukake et al., 2013). This extracellular form of the 
protein can also be found in human body fluids, including blood and CSF (Mollenhauer et al., 2011). The gradual spread of $\alpha$-syn pathology leads to a high concentration of extracellular $\alpha$-syn that can potentially damage healthy neurons. Moreover, recent biomarker studies have shown changes in the level of $\alpha$-syn in blood plasma from patients with PD (Li et al., 2007; Foulds et al., 2011), suggesting that $\alpha$-syn might cross the BBB. Later, radiolabeled $\alpha$-syn was traced in the bidirectional path from blood to the CNS and vice versa (Sui et al., 2014). Therefore, $\alpha$-syn can be considered as a potential biomarker for PD.

\section{Apolipoprotein A1 (ApoA1)}

ApoA1 is a 28 AA apolipoprotein with $\sim 28 \mathrm{kDa}$ molecular weight which is the main constituent of HDL particles (Brewer et al., 1983). This apolipoprotein is synthesized mostly by the liver and the small intestine and is responsible for gathering extra cholesterol from cells. ApoA1 in cooperation with apoE participates in lipid transport in the brain (Emamzadeh, 2017). ApoA1 together with another apolipoprotein, apoE are responsible for lipid transportation in the brain. Lower levels of one isoform of apoA1 and tetranectin are reported in the CSF of $\mathrm{PD}$ patients, suggesting that apoA1 is a potential biomarker for PD (Wang et al., 2010; Swanson et al., 2015). ApoA1 cannot be secreted from neurons, but as the main component of HDL, it is required for cholesterol transportation to the brain. Therefore, it possibly passes through the $\mathrm{BBB}$ and contribute to the protective roles of HDL. In PD, lower level of apoA1 means less efficient HDL and reduced brain cholesterol homeostasis and function (Vitali et al., 2014).

\section{RNA-Based PD Biomarkers}

Recent investigation of microRNAs (miRNAs) in PD point to their emerging role as potential PD biomarkers, especially due to their presence in CSF and peripheral circulation both free and in exosomes. miRNAs are small 21-24 nucleotide non-coding RNAs that regulate gene expression post-transcriptionally. Due to their ability to cross the BBB miRNAs have a high potential as convenient PD biomarkers. In a recent study Dos Santos et al. (2018) analyzed miRNA expression profile using next generation sequencing (NGS) in the CSF of early stage PD patients and controls. The authors have identified a miRNA-based biomarker panel for the early diagnosis of $\mathrm{PD}$, including the five best ranking variables (Let-7f-5p, miR-125a-5p, miR-151a-3p, miR-27a$3 p$ and miR-423-5p). The analysis showed high predictive value with $90 \%$ diagnostic sensitivity. Inclusion of $\alpha$-syn in the analysis further improves robustness of a miRNA-based panel. Several other teams confirmed that microRNAs may be used as new PD biomarkers suggesting a breakthrough for novel diagnostic and therapeutic approaches to this disease (Arshad et al., 2017; Vitali et al., 2018). Several other biomarkers are under investigation in a number of Medical Centers, the information about which can be found on the website: https://clinicaltrials.gov/ct2/results?cond=Parkinson\$ $+\$$ Disease\&term $=$ biomarker $\&$ cntry $=\&$ state $=\&$ city $=\&$ dist $=$.

\section{METABOLITE PROFILING}

Metabolic profiling of human tissues and/or biological fluids mirrors the complex interaction of genes, proteins and the environment of an individual. Proton $(1 \mathrm{H})$ and phosphorus (31P) magnetic resonance spectroscopy (MRS) are non-invasive imaging techniques that have been used to the study metabolites involved in energy metabolism, including ATP, lactate, creatine and other low molecular weight metabolite (Havelund et al., 2017). Significant alterations in metabolites have been described in $\mathrm{PD}$ patients and in animal models, including rise of lactate in striatum (Henchcliffe et al., 2008) and decrease of $N$-acetylaspartate/creatine ratios in advanced PD (SerajiBozorgzad et al., 2015). Alterations in alanine, branched-chain amino acids and fatty acid metabolism point to mitochondrial dysfunction in PD (Havelund et al., 2017).

\section{NEUROIMAGING BIOMARKERS}

Today's technology is able to detect brain's abnormalities in PD patients using imaging techniques, such as transcranial B-mode sonography (TCS), susceptibility-weighted imaging (SWI), diffusion weighted imaging (DWI) (Chung et al., 2009), positron emission tomography (PET) scan and, single-photon emission computed tomography (SPECT) scan.

\section{Transcranial B-Mode Sonography (TCS)}

Transcranial B-mode sonography monitors the blood flow velocity of brain's vessels by measuring the frequency of ultrasounds waves and their echoes. This inexpensive and reliable method shows the higher echogenicity of the SN in PD brains compared to normal group that possibly occurs due to increased iron and gliosis levels in SN of PD patients (Skoloudík et al., 2014). The increased iron level in $P D$ can be due to either alternation or malfunction of the $\mathrm{BBB}$. In PD the increase in the number of iron-transferring receptors including both transferrin receptors of $\mathrm{BBB}$ and iron-binding receptors of neurons can lead to accumulation of iron in SN (Hare et al., 2013).

\section{Magnetic Resonance Imaging (MRI)}

Diffusion weighted imaging is a form of MRI that measures the rate of water diffusion through a tissue to determine the structural details of that tissue. The higher measured diffusivity means the greater mobility of water molecules that can be due to the death of cells and the reduction of the region volume. This technique can differentiate $\mathrm{PD}$ from multiple system atrophy (MSA) in the early stage, while the clinical symptoms of these disorders are similar. In particular, the higher diffusivity of water in middle cerebellar peduncles in MSA patients in comparison to PD patients has been reported using DWI (Chung et al., 2009). DWI can also differentiate patients with progressive supranuclear palsy (PSP) from PD patients by detecting abnormalities in basal ganglia (Seppi et al., 2003). More traditional MRI methods, such as high-resolution 3-Tesla T1weighted MRI can also detect the reduced volume of caudate and 
putamen in PD patients in compared to controls (Saeed et al., 2017).

\section{Single-Photon Emission Computed Tomography (SPECT) Scan}

Both PET and SPECT scans can detect the early onset of PD and loss of dopaminergic neurons using radiotracers and computer techniques to generate $3 \mathrm{D}$ images. The majority of radiotracers are non-invasive radiopharmaceuticals with a short lifetime that usually decay soon after the imaging is complete. Moreover, the 3D images of PET and SPECT scans reveal function of an organ, whereas MRI can only monitor the anatomy and structure (Histed et al., 2012).

The SPECT scan radiotracers have a longer life-time in comparison to PET radiotracers. They mostly are ${ }^{123}$ iodine $\left({ }^{123} \mathrm{I}\right)$ and ${ }^{99 \mathrm{~m}}$ technetium $\left({ }^{99 \mathrm{~m}} \mathrm{Tc}\right)$ that emit gamma rays. The DAT-SPECT imaging can monitor degeneration of presynaptic terminals in dopaminergic neurons by visualizing DAT quantity. This method is a good way to diagnose reduction of DAT in the brain, and importantly it can't distinguish PD and other Parkinsonian Syndromes. The DAT gammaemitting ligands, such as ${ }^{123} \mathrm{I}$-iometopane $\left({ }^{123} \mathrm{I}-\beta\right.$-CIT), ${ }^{123} \mathrm{I}$-ioflupane $\quad\left({ }^{123} \mathrm{I}\right.$-FP-CIT), ${ }^{123} \mathrm{I}$-altropane $\quad\left({ }^{123} \mathrm{I}-\mathrm{IPT}\right)$ are the most common DAT-density SPECT tracers. These ligands are derivatives of tropane and dopamine reuptake inhibitors that target DAT (Wang et al., 2012; Brooks, 2016).

Single-photon emission computed tomography also employs dopamine D2 receptor radioligands that are dopamine antagonists. They include ${ }^{123}$ I-iodobenzamide ( ${ }^{123} \mathrm{I}$-IBZM) (Reiche et al., 1995), ${ }^{123} \mathrm{I}-\mathrm{IBF}$ (Sasaki et al., 2003), and ${ }^{123} \mathrm{I}-$ epidepride (Pirker et al., 1997). ${ }^{123} \mathrm{I}$ - $2^{\prime}$-iodospiperone (2'-ISP) is also used in some studies to monitor D2 dopamine receptors. Although this radiotracer can distinguish between PD and other form of parkinsonism due to the pattern of its uptake in basal ganglia, it produces a high imaging background and needs to be modified to improve its performance (Yonekura et al., 1995).

The number of vesicular acetylcholine transporter (VAChT) can be monitored by SPECT radiotracers as an approach for $\mathrm{PD}$ early diagnosis. Acetylcholine $(\mathrm{ACh})$ is a neurotransmitter that is in balance with dopamine in healthy people. The death of dopaminergic neurons and reduction of dopamine levels in PD are associated with increased Ach. ${ }^{123}$ I-iodobenzovesamicol $\left({ }^{123} \mathrm{I}\right.$-IBVM) binds to VAChT and reveals the density of acetylcholine containing vesicles. Reduction of VAChT in parietal and occipital lobes in PD patients without dementia and reduced VAChT in all lobes of the cerebral cortex in PD patients with dementia has been established by this SPECT radiotracer (Niethammer et al., 2012).

${ }^{123}$ I-metaiodobenzylguanidine $\quad\left({ }^{123} \mathrm{I}-\mathrm{MIBG}\right)$ is another radiotracer that can distinguish between PD and MSA (Goldstein, 2001). The heart-to-mediastinum ration of ${ }^{123} \mathrm{I}$ MIBG uptake is impaired in idiopathic PD patients, but not in patients with MSA. PET/CT scanning of these PD patients illustrated also decreased FP-CIT striatal uptake (Oh et al., 2015).
MIBG scintigraphy allows to distinguish not only between PD versus MSA, but also between PD and DLB (Goldstein, 2001, 2013).

\section{Positron Emission Tomography (PET) Scan}

The PET scan radiotracers emit electron anti-particles (positrons) that are positively charged with the same mass as an electron. The presence of presynaptic DAT in dopaminergic neurons of striatum and $\mathrm{SN}$ can be assessed with ${ }^{18} \mathrm{~F}$ and/or ${ }^{11} \mathrm{C}$ radiolabeled dopamine analogs. These DAT radioligands include ${ }^{18} \mathrm{~F}$-dopamine ( ${ }^{18} \mathrm{~F}$-dopa) (Ibrahim et al., 2016), ${ }^{18} \mathrm{~F}$-FE-PE2I (Fazio et al., 2015), ${ }^{18} \mathrm{~F}-\beta$-CFT (Rinne et al., 1999), ${ }^{18} \mathrm{~F}$-LBT999 (Arlicot et al., 2017), and ${ }^{11} \mathrm{C}$-methylphenidate. The VMAT2 quantification is also possible by using either ${ }^{11} \mathrm{C}$ or ${ }^{18} \mathrm{~F}$ radiolabeled dihydrotetrabenazine (DTBZ) (Tong et al., 2008; Lin et al., 2013). Because of dopaminergic cell loss and subsequent loss of VMAT2, the PET signal of radiolabeled DTBZ is lower in PD patients than in controls. Both DAT and VMAT2 radioligands can detect the early signs of dopaminergic damage, although PD may not be differentiated from atypical Parkinsonism with dopaminergic dysfunction. ${ }^{11} \mathrm{C}-\mathrm{MP} 4 \mathrm{~A}$ is another PET radiotracer that monitors the level of acetylcholinesterase (AChE) activity. AChE hydrolyses deactivates Ach and terminates the signal. Impairment of cholinergic system and reduction of cortical AChE has been assessed by ${ }^{11} \mathrm{C}-\mathrm{MP} 4 \mathrm{~A}-\mathrm{PET}$ scan. AChE activity reduces more in PDD than in PD, indicating that cholinergic dysfunction is correlated with dementia in PD (Bohnen et al., 2006).

\section{PARKINSON'S DISEASE TREATMENT}

The development of neuroprotective drugs for $\mathrm{PD}$ is an important unmet medical need, since this disease progressively impair the patients' quality of life and functionality in activities of daily living. The identification of new therapeutic targets is therefore of great importance. Although different medications and therapies for controlling PD symptoms are currently available, no cure for PD exists. The development of treatments for PD, based on patients' symptoms and needs, vary from different medications to rehabilitation or even surgery. PD includes different clinical entities observed in several studies investigating the existence of PD subtypes. A cluster analysis permits to identify distinct PD subtypes according to the relevance of both motor and non-motor symptoms and select therapeutic approach according to cluster symptoms presentation (Lauretani et al., 2014).

\section{MEDICATIONS}

The most common therapy for PD includes different commercially available medications that treat the lack of dopamine in the SN. These medications can temporarily alleviate PD symptoms in different ways by enhancing dopamine level, mimicking the role of dopamine or inhibiting dopamine 
oxidative metabolism, which leads to the generation of reactive oxygen species (ROS) (Goldenberg, 2008). Formation of protein aggregates that lead to neuronal cell death is another important target for PD treatment. Among different PD medications, levodopa (L-dopa, L-3,4-dihydroxyphenylalanine) is an effective drug. Levodopa is the immediate metabolic precursor of dopamine which is produced by $\mathrm{TH}$ from L-tyrosine. In the dopaminergic neurons, dopa-decarboxylase converts levodopa into dopamine. The orally taken levodopa can be decarboxylated in peripheral sites before reaching the CNS. Therefore, levodopa is available in combination with carbidopa or benserazide that are peripheral inhibitors of Dopa decarboxylase, but do not pass through the $\mathrm{BBB}$. Unchanged levodopa in the presence of decarboxylase peripheral inhibitors can penetrate into the CNS and is used as a precursor of dopamine (Goldenberg, 2008).

Levodopa, is more efficiently transformed into DA after vesicle storage by the serotonergic neurons, rather than the dopaminergic ones of the nigrostriatal system. Since the serotonergic distribution throughout the brain is very different than the dopaminergic one, this causes the well-known side effects of L-DOPA therapy and reduces its efficiency as a drug (De Deurwaerdère et al., 2017).

Sinemet was the first brand of carbidopa/levodopa combination in the pharmaceutical market (Scriabine, 1999). Rytary and duopa are two newly approved medications for PD by the Food and Drug Administration (FDA). Xadago (safinamide) is recently approved medication for PD patients who do not benefit from levodopa/carbidopa. Rytary is manufactured by Impax Laboratories as an oral capsule containing carbidopalevodopa together with entacapone to prolong its effects. Doupa produced by AbbVie Company is used for the treatment of motor fluctuations in advanced PD. Doupa is an enteral gel made of levodopa-carbidopa that is pumped to patient intestines (Olanow et al., 2014).

A group of dopamine agonists are agents that bind to the dopaminergic post-synaptic receptors and trigger the same signal as dopamine itself. This group include pergolide, pramipexole dihydrochloride, ropinirole hydrochloride, rotigotine, and apomorphine hydrochloride (Jankovic and Aguilar, 2008).

Inhibitors of MAOB - selegiline and rasagiline are also available as PD medications. Monoamine oxidase isoforms, including MAOA and MAOB, located on the outer membrane of mitochondria are involved in the oxidative deamination of biogenic amines, such as neurotransmitters and xenobiotic amines, e.g., 1-methyl-4-phenyl-1,2,3,6-tetrahydropyridine (MPTP) (Bach et al., 1988). The MAOs have a significant effect on the course of $\mathrm{PD}$, because they are involved in the metabolism of dopamine. Oxidative metabolism of dopamine in the dopaminergic cells of SN by MAOs leads to ROS generation, oxidative damage and cell death (Reiter, 1995). Moreover, MAOB catalyzes the conversion of MPTP into 1-methyl-4phenylpyridine (MPP+) which is responsible for parkinsonism in intravenous drug users (Langston, 1996). Selegiline and rasagiline can protect neurons against oxidative damage induced by dopamine metabolites diminishing MAOB activity. Moreover, several substances, such as entacapone and tolcapone that inhibit catechol-o-methyl transferase (COMT) are available as alternative PD medications. These two medications block the conversion of levodopa into methylated levodopa. Therefore, inhibition of COMT activity by these medications can extend the existence of functional levodopa preventing its degradation (Goldenberg, 2008).

Additionally, some other chemicals can be considered as potential PD medicines. Rapamycin can be a useful treatment for PD as an up-regulator of autophagy. Rapamycin induces autophagy in cells by inhibition of a specific kinase activity called mTOR. Autophagy is a potential target for PD treatment, since it initiates the clearance of protein aggregates and inhibits apoptosis (Hochfeld et al., 2013). Adenosine A2A receptor antagonists, such as caffeine also reduces the risk of PD. Transgenic mice with mutant $\alpha$-syn and deleted adenosine A2A receptor genes are protected against $\mathrm{PD}$. Thus, A2A receptor antagonists are potential candidates for prevention and treatment of PD (Kachroo and Schwarzschild, 2012).

Formation of protein aggregates that leads to neuronal cell death is a promising target for PD treatment. In January 2015, Neuropore Therapies has announced phase I clinical trial of a new drug, NPT200-11 (UCB-1332) that inhibits oligomerization of $\alpha$-syn (Oertel, 2017). Another potential drug modulating the aggregation of $\alpha$-syn blocking or reducing the conversion of monomers to oligomers or later on to fibrils is ANLE138b (Levin et al., 2014). Several promising compounds are under development and/or in preclinical testing that may enhance autophagy of $\alpha$-syn. Recent screening of compounds protecting cells from $\alpha$-syn induced neurodegeneration identified a non-selective phosphodiesterase (PDE) inhibitor dipyridamole. Importantly, PDE1 inhibition also protects dopaminergic neurons from $\alpha$-syn induced degeneration in mouse SN. PDE inhibitors are currently at preclinical testing (Höllerhage et al., 2017). Another antiaggregation compound - a natural product squalamine displaces $\alpha$-syn from the surfaces of lipid vesicles, thereby blocking the first steps in its aggregation process. Furthermore, squalamine suppresses the toxicity of $\alpha$-syn oligomers by inhibiting their interactions with lipid membranes (Perni et al., 2017).

\section{SURGERY}

Deep brain stimulation therapy is rarely used for certain types of brain-related disorders including PD, dystonia, obsessivecompulsive disorder and treatment resistant depression (Herrington et al., 2016). When PD symptoms are very severe and medications cannot moderate them, surgery and DBS can be considered as the final options for the treatment. It involves sending electrical impulses to certain parts of the brain (usually SN or globus pallidus, which communicate with the $\mathrm{SN}$ ) by a neurostimulator device that is a brain implant known as a 'brain pacemaker.' The target area of DBS is usually the subthalamic nucleus (STN). The stimulation of the dorsolateral STN border alongside the surgery can improve its efficiency (Herzog et al., 2004). Later it was found that stimulation of caudal zona incerta (cZI) can be more effective with fewer complications after the surgery (Plaha et al., 2006). Stimulation 
of neurons may also lead to neurogenesis and neuroplasticity and thus can improve for a long time motor problems, such as dyskinesia and tremor, and all other levodopa-responsive symptoms, for a long time. However, there are two problems with DBS, namely a 3- to 6-month waiting period required for optimal results and the possibility of brain infection (Bronstein et al., 2011).

\section{GENE THERAPY}

The development of gene therapy of PD has made a major progress in a recent decade. Advanced PD does not give a good response to levodopa therapy. Broaden loss of dopaminergic neurons is accompanied by reduction in aromatic amino acid decarboxylase (AADC) levels that converts L-DOPA to dopamine. After successful preclinical studies, adeno-associated viral vectors carrying human AADC gene are recently delivered into putaminal neurons and subthalamic nucleus of PD patients. In this method, sufficient amount of dopamine production can be controlled by taking adequate levodopa dose. Orally taken levodopa can be converted into dopamine by AADC and sooth PD symptoms (Muramatsu et al., 2010). Safety and efficiency of the method have been proven over 4 years by annually PET imaging from patients who received specific dosages of AAV2-hAADC (Mittermeyer et al., 2012). Another target for gene therapy in PD is glutamic acid decarboxylase (GAD) that facilitate production of GABA in GABA-ergic neurons in the subthalamic nucleus. GABA as an inhibitory neurotransmitter regulates muscle tone and improve motor functions (Watanabe et al., 2002). Lack of dopamine in PD causes activation of the subthalamic nucleus and unnecessary muscular responses that GABA by its inhibitory effect can significantly improve. This method can be compared with DBS that by sending electric shocks to subthalamic nucleus reduces its hyperactivity and improve motor impairment (Coune et al., 2012). The human trial of this method was performed by bilateral injection of AAV2-GAD in the subthalamic nucleus of patients with advanced PD. This approach has shown safety and efficiency, although it needs more investigation to be considered as a treatment (LeWitt et al., 2011). Therapeutic effect of glial cell line-derived neurotrophic factor (GDNF) on neuronal function in non-human models of PD encouraged scientists to inject it directly into putamen of PD patients. This surgery helped patients with improved movement, reduced dyskinesia and increased dopamine storage in the putamen (Gill et al., 2003). Therefore, GDNF is a possible option for gene therapy. Neurturin gene is another candidate for PD gene therapy. Neurturin is a neurotrophic factor important for survival and differentiation of dopaminergic neurons (Lin et al., 1993). The human trial of this factor was conducted by bilateral injection of vector AAV2-neurturin (CERE-120) into the putamen biomarkers patients with advanced PD (Bartus et al., 2013). Injected neurturin cannot spread into SN and play its therapeutic role because of vast axonal transport defects in PD patients. Another consequence of this method may be the accumulation of $\alpha$-syn that leads to downregulation of neurturin expression (Bartus et al., 2014).

\section{NON-GENETIC RISK FACTORS OF PARKINSON DISEASE}

Only $10-15 \%$ of PD cases are early onset familial PD, while the remaining cases are idiopathic pointing to an important role of non-genetic and environmental factors in PD pathogenesis. Exposure to environmental toxins can cause dopaminergic cell death. The accumulation of heavy metals in the SN enhances the risk of developing PD. The effect of exposure to heavy metals could increase oxidative stress in dopaminergic cells, leading to $\mathrm{PD}$. MAO in the presence of oxygen can mediate dopamine oxidation in vitro into 3,4-dihydroxylphenylacetaldehyde (DOPAL). DOPAL initiates oligomerization of $\alpha$-syn into non-fibrillar, SDS-resistant aggregates (Burke, 2003). However, another study has revealed that inhibition of MAO to stop the production of DOPAL is not sufficient to reduce oligomerization of $\alpha$-syn (Burke, 2003). The auto-oxidation of dopamine to dourmine quinone (DAQ) can also increase both formation and secretion of non-fibrillar $\alpha$-syn oligomers, thus promoting pathogenic $\alpha$-syn transmission to adjacent neurons and glia (Lee et al., 2011). Neuromelanin pigment is highly expressed in dopaminergic neurons, preventing oxidative stress related to the accumulation of cytosolic dopamine. On the other hand, dying neurons in PD brains release neuromelanin that activates neuroglia and triggers neuroinflammation (Zucca et al., 2014). Moreover, lipidated neuromelanin can interact with $\alpha$-syn and trigger its aggregation into the insoluble complex in PD patients (Double and Halliday, 2006).

Genetic polymorphisms of cytochrome P450 2D6 (CYP2D6) an enzyme involved in metabolizing environmental toxins, are also related to the development of PD. For example, CYP2D6 deficient metabolizers are two times higher at risk of developing $\mathrm{PD}$ if they are also exposed to pesticides. Therefore, sufficient levels of CYP2D6 activity are required for the metabolism of pesticides (e.g., organophosphates, atrazine), which are linked to the pathogenesis of PD (Elbaz and Tranchant, 2007).

Reactive oxygen species and thus oxidative stress is also known as a pathological factor in PD. NADPH oxidase2 enzyme (NOX2) is a membrane-bound oxidase present primarily in phagocytes generating ROS in phagosomes to kill bacteria. NOX2-derived ROS also damages dopaminergic neurons. Dopaminergic neurons in NOX2-knockout mice start to degenerate faster than similar cells in wild-type controls after administration of MPTP (Brieger et al., 2012).

In 1956 two neurologists, Poskanzer and Schwab hypothesized that PD is related to influenza infection (Estupinan et al., 2013). They studied a group of PD patients and revealed that age of disease onset is shifted in the direction of an age group who were born before or during the influenza pandemic in 1918 and mostly had been infected by the flu virus. However, other studies showed that influenza infection can cause PD-like symptoms, but cannot increase the risk of developing PD (Estupinan et al., 2013). Another hypothesis proposes that Toxoplasma gondii, an 
intracellular parasite causing toxoplasmosis, may increase the risk of PD. The parasite in the brain infected those areas that are affected in PD, including basal ganglia (Miman et al., 2010), although other studies did not get a similar result (Mahami Oskouei et al., 2016).

\section{GENETIC FORMS AND GENETIC RISK FACTORS OF PD}

Although most cases of PD are idiopathic forms of the disease, about $15 \%$ of PD patients are recognized as having a first-degree family member with this disease. Recently, the genetic factors and gene loci involving in autosomal dominant and autosomal recessive forms of $\mathrm{PD}$ have been discovered due to advanced molecular genetics (Samii et al., 2004; Karimi-Moghadam et al., 2018) (Tables 1, 2). The mutations in several genes, including $\alpha$-syn, LRRK2, PINK1, Parkin, DJ-1, VPS35 and GBA1 are linked to PD (Zeng et al., 2018). In addition to mutations in these genetic loci, polymorphisms, and trinucleotide repeats are recognized as PD genes, or susceptibility factors for PD (Table 3).

\section{EPIGENETIC RISK FACTORS OF PD}

Epigenetics refer to chromatin alternations, including DNA methylation and histone post translational modifications that can alter gene expression without changes in DNA sequence. These modifications can be inherited, but environmental factors including nutritional, chemical and physical factors can also affect epigenetics (Surguchov et al., 2017). In sporadic form of PD involvement of environmental factors in initiation and progression of disease emerging an idea that epigenetic plays an important role in PD (Feng et al., 2015). One of the examples of epigenetic mechanism in $\mathrm{PD}$ is modification of $\alpha$-syn gene (SNCA). SNCA has two CpG islands with the first one being located in exon 1 (CpG-1) and the second one (CpG-2) within intron 1. Transcription factors (TFs) GATA and ZSCAN21 bind to the intron 1 CpG-2 island and modulate transcription of $\alpha$-syn. CpG-2 methylation prevents the binding of the TFs to SNCA and subsequently inhibits the overexpression of $\alpha$-syn. Interestingly, binding of transcription factors to $\alpha$-syn (Iwata et al., 2001) and another member of the synuclein family, $\gamma$-synuclein (Surgucheva and Surguchov, 2008), has been

TABLE 1 | Autosomal recessive and X-linked genes involved in Parkinson's disease.

\begin{tabular}{|c|c|c|c|c|}
\hline Inheritance pattern & Locus & Chr. location & Mutation site in & Involved protein \\
\hline \multirow[t]{8}{*}{ Autosomal recessive } & PARK2/PARKN & $6 q 25.2-q 27$ & Parkin & Ubiquitin-protein ligase (Kitada et al., 1988) \\
\hline & PARK6 & $1 p 36$ & PINK1 & PTEN-induced putative kinase 1 (Valente et al., 2004) \\
\hline & PARK7 & $1 p 36.23$ & DJ1 & Oncogene DJ1 (van Duijn et al., 2001) \\
\hline & PARK9 & $1 \mathrm{p} 36$ & ATP13A2 & Lysosomal type 5 P-type ATPase (Ramirez et al., 2006) \\
\hline & PARK14 & $22 q 13.1$ & PLA2G6 & Phospholipase A2 (Paisan-Ruiz et al., 2009; Shi et al., 2011) \\
\hline & PARK15 & $22 q 12-q 13$ & FBXO7 & F-BOX only protein 7 (Paisan-Ruiz et al., 2009) \\
\hline & PARK19 & $1 \mathrm{p} 32$ & DNAJC6 & Putative tyrosine-protein phosphatase auxilin (Koroglu et al., 2013) \\
\hline & PARK20 & $21 q 22$ & SYNJ1 & Synaptojanin-1 (Krebs et al., 2013) \\
\hline X-linked & PARK12 & Xq21-q25 & TAF1 & TFIID subunit 1 (Graeber and Muller, 1992) \\
\hline
\end{tabular}

TABLE 2 | Autosomal dominant genes involved in Parkinson's disease.

\begin{tabular}{|c|c|c|c|c|}
\hline Inheritance pattern & Locus & Chr. location & Mutation site & Involved protein \\
\hline \multirow[t]{11}{*}{ Autosomal dominant } & PARK1 & $4 q 21$ & SNCA & $\alpha$-Syn (Xu et al., 2017) \\
\hline & PARK3 & $2 \mathrm{p} 13.2$ & $S P R$ & $\begin{array}{l}\text { Sepiapterin reductase in } \mathrm{BH} 4 \text { pathway } \\
\text { (Karamohamed et al., 2003) }\end{array}$ \\
\hline & PARK4 & $4 q 21$ & Triplication of SNCA & $\alpha$-Syn (Singleton et al., 2003) \\
\hline & PARK5 & $4 p 14$ & UCHL1 & $\begin{array}{l}\text { Ubiquitin C-terminal hydrolase (Leroy et al., } \\
\text { 1998) }\end{array}$ \\
\hline & PARK8 & $12 q 12$ & LRRK2 & $\begin{array}{l}\text { Leucine-reach repeat kinase } 2 \text { (Zimprich et al., } \\
\text { 2004) }\end{array}$ \\
\hline & PARK11 & $2 q 37$ & GIGYF2 & $\begin{array}{l}\text { GRB10-interacting GYF protein } 2 \text { (Lautier et al., } \\
\text { 2008; Tan et al., 2009) }\end{array}$ \\
\hline & PARK13 & $2 \mathrm{p} 12$ & HTRA2 & $\begin{array}{l}\text { HTRA serine peptidase (Strauss et al., 2005; } \\
\text { Lin et al., 2011) }\end{array}$ \\
\hline & PARK16 & $1 \mathrm{q} 32$ & Multiple independent sites? & Unknown (Satake et al., 2009; Li et al., 2011) \\
\hline & PARK17 & $16 p 12.1-q 12.1$ & VPS35 & $\begin{array}{l}\text { Vacuolar protein sorting } 35 \text { (Vilariño-Güell et al., } \\
\text { 2011) }\end{array}$ \\
\hline & PARK18 & $3 q 27$ & EIF4G1 & $\begin{array}{l}\text { Eukaryotic translation initiation factor } 4 \text { gamma } \\
1 \text { (Chartier-Harlin et al., 2011) }\end{array}$ \\
\hline & PARK21 & $3 q 22$ & DNAJC13 & $\begin{array}{l}\text { DNAJ-domain-bearing protein (Appel-Cresswell } \\
\text { et al., 2014; Vilariño-Güell et al., 2014) }\end{array}$ \\
\hline
\end{tabular}


TABLE 3 | Susceptibility factors of Parkinson's disease.

\begin{tabular}{|c|c|c|c|c|}
\hline Susceptibility factors & Involved gene & Chr. location & Putative function & Phenotype \\
\hline & MAPT & $17 \mathrm{q} 21.1$ & Microtubule-associated protein tau & $\begin{array}{l}\text { Supranuclear palsy, Dementia (Das } \\
\text { et al., 2009) }\end{array}$ \\
\hline & MC1R & $16 q 24.3$ & $\begin{array}{l}\text { Melanocyte-stimulating hormone } \\
\text { receptor }\end{array}$ & Albinism (Tell-Marti et al., 2015) \\
\hline & $A D H 1 C$ & $4 q 23$ & Alcohol dehydrogenase $1 \mathrm{C}$ & $\begin{array}{l}\text { Alcohol dependence (Buervenich et al., } \\
\text { 2005) }\end{array}$ \\
\hline & HLA & $6 p 21.3$ & Major histocompatibility complex & Imamura et al., 2003 \\
\hline & ATXN2 & $12 \mathrm{q} 24.1$ & Ataxin-2 & $\begin{array}{l}\text { Spinocerebellar ataxia } 2 \text { (Charles et al., } \\
\text { 2007) }\end{array}$ \\
\hline & ATXN3 & $14 q 21$ & Ataxin-3 & $\begin{array}{l}\text { Machado-Joseph disease } \\
\text { (Gwinn-Hardy et al., 2001) }\end{array}$ \\
\hline & NR4A2 & $2 q 24.1$ & $\begin{array}{l}\text { Nuclear receptor subfamily } 4 \text { group A } \\
\text { member } 2 \text { (transcription factor) }\end{array}$ & Le et al., 2003 \\
\hline
\end{tabular}

described, suggesting that synuclein family members are involved in various complex mechanisms of gene expression regulation. Therefore, their role in $\mathrm{PD}$ is not limited to the formation of toxic aggregates, but may be complemented by participation in regulatory processes.

Matsumoto et al. (2010) found that CpGs in SNCA were hypermethylated in controls, but not methylated in PD patients, suggesting that methylation was an epigenetic risk factor for $\mathrm{PD}$ that is related to the pathogenesis of $\alpha$-syn. In $\mathrm{PD}$, demethylated SNCA codes for a high amount of $\alpha$-syn that may initiate aggregation and promote neurodegeneration. Additionally, the levels of nuclear DNA (cytosine-5') methyltransferase 1 (DNMT1) in post-mortem PD brains is lower than in control brains. This methylase epigenetically suppresses gene expression by DNA methylation, and its reduced level in PD may be associated with SNCA hypomethylation.

Epigenetic modifications in other genes are also implicated in contributing to PD, including tumor necrosis factor $\alpha$ (TNF$\alpha)$, PARK16, transmembrane glycoprotein NMB (GPNMB), and syntaxin-1B (STX1B) genes. Hypomethylation of the TNF- $\alpha$ promoter, hypermethylation of a CpG dinucleotide in synphilin1, STX1B and hypermethylation of multiple CpG sites proximal to GPNMB are all described in PD (Yang et al., 2017). Moreover, the epigenetic changes in mitochondrial DNA (mtDNA) can also trigger PD. Several studies show the hypo-methylation and hyper-hydroxymethylation of mtDNA displacement loop (Dloop) in the SN of PD brains (Iacobazzi et al., 2013; Chuang et al., 2017).

\section{CONCLUSION}

Pathology of PD is complex and include a combination of genetics, epigenetics and environmental factors. Current medical, pathological, and experimental data support the Braak hypothesis (Braak et al., 2003) of spatiotemporal spread of PD pathology involving $\alpha$-syn propagation from the gastrointestinal and olfactory system via transsynaptic cell-to-cell transfer through the vegetative nervous systems to the CNS. Many non-motor symptoms, including sleep disorders, olfactory deficiency, hyposmia (reduced ability to smell and to detect odors), constipation and others may play an important role as successful, future diagnostic to target $\mathrm{PD}$ pathology and mechanisms during the initial stages of disease (Reichmann et al., 2016). Important contributing factors to $\mathrm{PD}$ are dysfunctions of mitochondria and endoplasmic reticulum, impairment of autophagy and endocytosis, and deregulation of immunity. Despite intensive investigation of PD mechanism the disease is still incurable. Future challenges for physicians and researchers working in the field of PD and similar disorders will be directed to the identification of biomarkers for an early diagnosis of these diseases at preclinical stage. New biomarkers should follow the progression of the disease and determine key metabolomic alterations to identify potential targets for intervention. Future tasks should be also directed to the development and application of preventive measures to stop or reduce disease progression at pre-symptomatic stages and the finding of novel antiparkinsonian drugs with specific neuroprotective effects on the dopaminergic system. In addition to conservative approach based on the identification of new protein biomarkers in blood, plasma and CSF, there is a growing hope that analysis of microRNAs may greatly contribute to early diagnosis of this disease. The development of induced pluripotent stem cell (iPSC) and genome editing technique open new hopes for the treatment of several human diseases, especially genetic disorders. For PD which is predominantly sporadic disease and 
a mix of several relatively rare genetic causes these methods gave the opportunity to develop new models and study phenotypes in both genetic and sporadic cases to piece together pathogenic pathways involving their gene products.

\section{AUTHOR CONTRIBUTIONS}

FE designed the article contents and wrote the original manuscript. AS revised and edited the manuscript, searched for additional related literature and discussed the writing with FE.

\section{REFERENCES}

Angot, E., and Brundin, P. (2009). Dissecting the potential molecular mechanisms underlying alpha-synuclein cell-to-cell transfer in Parkinson's disease. Parkinsonism Relat. Disord. 15(Suppl. 3), S143-S147. doi: 10.1016/ S1353-8020(09)70802-8

Appel-Cresswell, S., Rajput, A. H., Sossi, V., Thompson, C., Silva, V., McKenzie, J., et al. (2014). Clinical, positron emission tomography, and pathological studies of DNAJC13 p.N855S parkinsonism. Mov. Disord. 29, 1684-1687. doi: 10.1002/ mds. 26019

Arlicot, N., Vercouillie, J., Malherbe, C., Bidault, R., Gissot, V., Maia, S., et al. (2017). PET imaging of dopamine transporter with 18F-LBT999: first human exploration. J. Nucl. Med. 58:1276. doi: 10.1111/j.1527-3458.2007.00033.x

Arshad, A. R., Sulaiman, S. A., Saperi, A. A., Jamal, R., Mohamed Ibrahim, N., and Abdul Murad, N. A. (2017). MicroRNAs and target genes as biomarkers for the diagnosis of early onset of Parkinson disease. Front. Mol. Neurosci. 10:352. doi: 10.3389/fnmol.2017.00352

Bach, A. W., Lan, N. C., Johnson, D. L., Abell, C. W., Bembenek, M. E., Kwan, S.-W., et al. (1988). cDNA cloning of human liver monoamine oxidase A and B: molecular basis of differences in enzymatic properties. Proc. Nat. Acad. Sci. U.S.A. 85, 4934-4938. doi: 10.1073/pnas.85.13.4934

Bartus, R. T., Baumann, T. L., Siffert, J., Herzog, C. D., Alterman, R., Boulis, N., et al. (2013). Safety/feasibility of targeting the substantia nigra with AAV2neurturin in Parkinson patients. Neurology 80, 1698-1701. doi: 10.1212/WNL. 0b013e3182904faa

Bartus, R. T., Weinberg, M. S., and Samulski, R. J. (2014). Parkinson's disease gene therapy: success by design meets failure by efficacy. Mol. Ther. 22, 487-497. doi: $10.1038 / \mathrm{mt} .2013 .281$

Bentea, E., Verbruggen, L., and Massie, A. (2017). The proteasome inhibition model of Parkinson's disease. J. Parkinsons Dis. 7, 31-63. doi: 10.3233/JPD160921

Berendse, H. W., Booij, J., Francot, C. M., Bergmans, P. L., Hijman, R., and Stoof, J. C. (2001). Subclinical dopaminergic dysfunction in asymptomatic Parkinson's disease patients' relatives with a decreased sense of smell. Ann. Neurol. 50, 34-41. doi: 10.1002/ana.1049

Bernis, M. E., Babila, J. T., Breid, S., Wüsten, K. A., Wüllner, U., and Tamgüney, G. (2015). Prion-like propagation of human brain-derived alphasynuclein in transgenic mice expressing human wild-type alpha-synuclein. Acta Neuropathol. Commun. 3:75. doi: 10.1186/s40478-015-0254-7

Blandini, F., Sinforiani, E., Pacchetti, C., Samuele, A., Bazzini, E., and Zangaglia, R. (2006). Peripheral proteasome and caspase activity in Parkinson disease and Alzheimer disease. Neurology 66, 529-534. doi: 10.1212/01.wnl.0000198511. 09968.b3

Bohnen, N. I., Albin, R. L., Koeppe, R. A., Wernette, K. A., Kilbourn, M. R., Minoshima, S., et al. (2006). Positron emission tomography of monoaminergic vesicular binding in aging and Parkinson disease. J. Cereb. Blood Flow Metab. 26, 1198-1212. doi: 10.1038/sj.jcbfm.9600276

Braak, H., Del Tredici, K., Rüb, U., de Vos, R. A., Jansen Steur, E. N., and Braak, E. (2003). Staging of brain pathology related to sporadic Parkinson's disease. Neurobiol. Aging 24, 197-211. doi: 10.1016/s0197-4580(02)00065-9

Brewer, H. B. Jr., Fairwell, T., Kay, L., Meng, M., Ronan, R., Law, S., et al. (1983). Human plasma proapoA-I: isolation and amino-terminal sequence. Biochem. Biophys. Res. Commun. 113, 626-632. doi: 10.1016/0006-291X(83)91772-2

\section{FUNDING}

This work was supported by an EC Framework 7 Marie Curie Fellowship Training Network Grant (NEURASYNC) for FE and by VA Merit Review grants 1I01BX000361 and the Glaucoma Foundation grant QB42308 for AS.

\section{ACKNOWLEDGMENTS}

FE acknowledges Professor David Allsop for his help and support.

Brieger, K., Schiavone, S., Miller, F. J., and Krause, K. H. (2012). Reactive oxygen species: from health to disease. Swiss Med. Wkly. 142:w13659. doi: 10.4414/ smw.2012.13659

Bronstein, J. M., Tagliati, M., Alterman, R. L., Lozano, A. M., Volkmann, J., Stefani, A., et al. (2011). Deep brain stimulation for Parkinson disease: an expert consensus and review of key issues. Arch. Neurol. 68:165. doi: 10.1001/ archneurol.2010.260

Brooks, D. J. (2016). Molecular imaging of dopamine transporters. Ageing Res. Rev. 30, 114-121. doi: 10.1016/j.arr.2015.12.009

Buervenich, S., Carmine, A., Galter, D., Shahabi, H. N., Johnels, B., Holmberg, B., et al. (2005). A rare truncating mutation in ADH1C (G78Stop) shows significant association with Parkinson disease in a large international sample. Arch. Neurol. 62, 74-78. doi: 10.1001/archneur.62.1.74

Buervenich, S., Sydow, O., Carmine, A., Zhang, Z., Anvret, M., and Olson, L. (2000). Alcohol dehydrogenase alleles in Parkinson's disease. Mov. Disord. 15, 813-818. doi: 10.1002/1531-8257(200009)15:5<813::AID-MDS1008>3.0. $\mathrm{CO} ; 2-\mathrm{Y}$

Burke, W. J. (2003). 3,4-dihydroxyphenylacetaldehyde: a potential target for neuroprotective therapy in Parkinson's disease. Curr. Drug Targets CNS Neurol. Disord. 2, 143-148. doi: 10.2174/15680070334 82913

Caronti, B., Antonini, G., Calderaro, C., Ruggieri, S., Palladini, G., Pontieri, F. E., et al. (2001). Dopamine transporter immunoreactivity in peripheral blood lymphocytes in Parkinson's disease. Neural. Transm. 108, 803-807. doi: 10.1007/s007020170030

Charles, P., Camuzat, A., Benammar, N., Sellal, F., Destee, A., Bonnet, A.-M., et al. (2007). Are interrupted SCA2 CAG repeat expansions responsible for parkinsonism? Neurology 69, 1970-1975.

Chartier-Harlin, M.-C., Dachsel, J. C., Vilarino-Guell, C., Lincoln, S. J., Lepretre, F., Hulihan, M., et al. (2011). Translation initiator EIF4G1 mutations in familial Parkinson disease. Am. J. Hum. Genet. 89, 398-406. doi: 10.1016/j.ajhg.2011. 08.009

Chuang, Y. H., Paul, K. C., Bronstein, J. M., Bordelon, Y., Horvath, S., and Ritz, B. (2017). Parkinson's disease is associated with DNA methylation levels in human blood and saliva. Genome Med. 9:76. doi: 10.1186/s13073-0170466-5

Chung, E. J., Kim, E. G., Bae, J. S., Eun, C. K., Lee, K. S., and Oh, M. (2009). Usefulness of diffusion-weighted MRI for differentiation between Parkinson's disease and Parkinson variant of multiple system atrophy. J. Mov. Disord. 2, 64-68. doi: 10.14802/jmd.09017

Ciechanover, A., and Kwon, Y. T. (2015). Degradation of misfolded proteins in neurodegenerative diseases: therapeutic targets and strategies. Exp. Mol. Med. 47:e147. doi: 10.1038/emm.2014.117

Clairembault, T., Kamphuis, W., Leclair-Visonneau, L., Rolli-Derkinderen, M., Coron, E., Neunlist, M., et al. (2014). Enteric GFAP expression and phosphorylation in Parkinson's disease. J. Neurochem. 130, 805-815. doi: $10.1111 /$ jnc. 12742

Coune, P. G., Schneider, B. L., and Aebischer, P. (2012). Parkinson's disease: gene therapies. Cold Spring Harb. Perspect. Med. 2:a009431. doi: 10.1101/cshperspect. a009431

Das, G., Misra, A. K., Das, S. K., Ray, K., and Ray, J. (2009). Microtubule-Associated Protein Tau (MAPT) influences the risk of Parkinson's disease among Indians. Neurosci. Lett. 460, 16-20. doi: 10.1016/j.neulet.2009.05.031 
De Deurwaerdère, P., Di Giovanni, G., and Millan, M. J. (2017). Expanding the repertoire of L-DOPA's actions: a comprehensive review of its functional neurochemistry. Prog. Neurobiol. 151, 57-100. doi: 10.1016/j.pneurobio.2016. 07.002

Dos Santos, M. C. T., Barreto-Sanz, M. A., Correia, B. R. S., Bell, R., Widnall, C., Perez, L. T., et al. (2018). miRNA-based signatures in cerebrospinal fluid as potential diagnostic tools for early tage Parkinson's disease. Oncotarget 9, 17455-17465. doi: 10.18632/oncotarget.24736

Double, K. L., and Halliday, G. M. (2006). New face of neuromelanin. J. Neural Transm. Suppl. 70, 119-123. doi: 10.1007/978-3-211-45295-0_19

El-Agnaf, O. M. A., Salem, S. A., Paleologou, K. E., Curran, M. D., Gibson, M. J., Court, J. A., et al. (2006). Detection of oligomeric forms of (-synuclein protein in human plasma as a potential biomarker for Parkinson's disease. FASEB J. 20, 419-425. doi: 10.1096/fj.03-1449com

Elbaz, A., and Tranchant, C. (2007). Epidemiologic studies of environmental exposures in Parkinson's disease. Neurol. Sci. 262, 37-44. doi: 10.1016/j.jns. 2007.06.024

Emamzadeh, F. N. (2016). Alpha-synuclein structure, functions, and interactions. J. Res. Med. Sci.? 21:29. doi: 10.4103/1735-1995.181989

Emamzadeh, F. N. (2017). Role of Apolipoproteins and $\alpha$-Synuclein in Parkinson's disease. J. Mol. Neurosci. 62, 344-355. doi: 10.1007/s12031-017-0942-9

Estupinan, D., Nathoo, S., and Okun, M. S. (2013). The demise of Poskanzer and Schwab's influenza theory on the pathogenesis of Parkinson's disease. Parkinsons Dis. 2013:167843. doi: 10.1155/2013/167843

Fazio, P., Svenningsson, P., Forsberg, A., Jönsson, E. G., Amini, N., Nakao, R., et al. (2015). Quantitative Analysis of ${ }^{18} \mathrm{~F}$-(E)-N-(3-Iodoprop-2-Enyl)$2 \beta$-Carbofluoroethoxy-3 $\beta$-(4'-Methyl-Phenyl) nortropane binding to the dopamine transporter in Parkinson disease. J. Nucl. Med. 56, 714-720. doi: 10.2967/jnumed.114.152421

Feng, Y., Jankovic, J., and Wu, Y. C. (2015). Epigenetic mechanisms in Parkinson's disease. J. Neurol. Sci. 349, 3-9. doi: 10.1016/j.jns.2014.12.017

Foulds, P. G., Mitchell, J. D., Parker, A., Turner, R., Green, G., Diggle, P., et al. (2011). Phosphorylated $\alpha$-synuclein can be detected in blood plasma and is potentially a useful biomarker for Parkinson's disease. FASEB J. 25, 4127-4137. doi: 10.1096/fj.10-179192

Fronczek, R., Overeem, S., Lee, S. Y., Hegeman, I. M., van Pelt, J., van Duinen, S. G., et al. (2007). Hypocretin (orexin) loss in Parkinson's disease. Brain 130, 1577-1585. doi: 10.1093/brain/awm090

Gill, S. S., Patel, N. K., Hotton, G. R., O’Sullivan, K., McCarter, R., Bunnage, M., et al. (2003). Direct brain infusion of glial cell line-derived neurotrophic factor in Parkinson disease. Nat. Med. 9, 589-595. doi: 10.1038/nm850

Goldenberg, M. M. (2008). Medical management of Parkinson's disease. P T 33, 590-606.

Goldstein, D. S. (2001). Cardiac sympathetic neuroimaging to distinguish multiple system atrophy from Parkinson disease. Clin. Auton. Res. 11, 341-342. doi: 10.1007/BF02292764

Goldstein, D. S. (2013). Sympathetic neuroimaging. Handb. Clin. Neurol. 117, 365-370. doi: 10.1016/B978-0-444-53491-0.00029-8

Goldstein, D. S., Holmes, C., Lopez, G. J., Wu, T., and Sharabi, Y. (2018). Cerebrospinal fluid biomarkers of central dopamine deficiency predict Parkinson's disease. Parkinsonism Relat. Disord. 50, 108-112. doi: 10.1016/j. parkreldis.2018.02.023

Graeber, M. B., and Muller, U. (1992). The X-linked dystonia-parkinsonism syndrome: clinical and molecular genetic analysis. Brain Pathol. 2, 287-295. doi: 10.1111/j.1750-3639.1992.tb00706.x

Gwinn-Hardy, K., Singleton, A., O'Suilleabhain, P., Boss, M., Nicholl, D., Adam, A., et al. (2001). Spinocerebellar ataxia type 3 phenotypically resembling parkinson disease in a black family. Arch. Neurol. 58, 296-299. doi: 10.1001/archneur.58. 2.296

Hagan, J. J., Leslie, R. A., Patel, S., Evans, M. L., Wattam, T. A., Holmes, S., et al. (1999). Orexin a activates locus coeruleus cell firing and increases arousal in the rat. Proc. Nat. Acad. Sci. U.S.A. 96, 10911-10916. doi: 10.1073/pnas.96.19.10911

Hare, D., Ayton, S., Bush, A., and Lei, P. (2013). A delicate balance: iron metabolism and diseases of the brain. Front. Aging Neurosci. 18:34. doi: 10.3389/fnagi.2013. 00034

Havelund, J. F., Heegaard, N. H. H., Færgeman, N. J. K., and Gramsbergen, J. B. (2017). Biomarker research in Parkinson's disease using metabolite profiling. Metabolites 7:E42. doi: 10.3390/metabo7030042
Henchcliffe, C., Shungu, D. C., Mao, X., Huang, C., Nirenberg, M. J., and Jenkins, B. G. (2008). Multinuclear magnetic resonance spectroscopy for in vivo assessment of mitochondrial dysfunction in Parkinson's disease. Ann. N. Y. Acad. Sci. 1147, 206-220. doi: 10.1196/annals.1427.037

Herrington, T. M., Cheng, J. J., and Eskandar, E. N. (2016). Mechanisms of deep brain stimulation. J. Neurophysiol. 115, 19-38. doi: 10.1152/jn.00281.2015

Herzog, J., Fietzek, U., Hamel, W., Morsnowski, A., Steigerwald, F., and Schrader, B. (2004). Most effective stimulation site in subthalamic deep brain stimulation for Parkinson's disease. Mov. Disord. 19, 1050-1054. doi: 10.1002/ mds. 20056

Histed, S. N., Lindenberg, M. L., Mena, E., Turkbey, B., Choyke, P. L., and Kurdziel, K. A. (2012). Review of functional/ anatomic imaging in oncology. Nucl. Med. Commun. 33, 349-361. doi: 10.1097/MNM.0b013e32834ec8a5

Hochfeld, W. E., Lee, S., and Rubinsztein, D. C. (2013). Therapeutic induction of autophagy to modulate neurodegenerative disease progression. Acta Pharmacol. Sin. 34, 600-604. doi: 10.1038/aps.2012.189

Höllerhage, M., Moebius, C., Melms, J., Chiu, W. H., Goebel, J. N., Chakroun, T., et al. (2017). Protective efficacy of phosphodiesterase-1 inhibition against alphasynuclein toxicity revealed by compound screening in LUHMES cells. Sci. Rep. 7:11469. doi: 10.1038/s41598-017-11664-5

Hong, Z., Shi, M., Chung, K. A., Quinn, J. F., Peskind, E. R., Galasko, D., et al. (2010). DJ-1 and alpha-synuclein in human cerebrospinal fluid as biomarkers of Parkinson's disease. Brain 133, 713-726. doi: 10.1093/brain/awq008

Iacobazzi, V., Castegna, A., Infantino, V., and Andria, G. (2013). Mitochondrial DNA methylation as a next-generation biomarker and diagnostic tool. Mol. Genet. Metab. 110, 25-34. doi: 10.1016/j.ymgme.2013.07.012

Ibrahim, N., Kusmirek, J., Struck, A. F., Floberg, J. M., Perlman, S. B., Gallagher, C., et al. (2016). The sensitivity and specificity of F-DOPA PET in a movement disorder clinic. Am. J. Nucl. Med. Mol. Imaging 6, 102-109.

Imamura, K., Hishikawa, N., Sawada, M., Nagatsu, T., Yoshida, M., and Hashizume, Y. (2003). Distribution of major histocompatibility complex class II-positive microglia and cytokine profile of Parkinson's disease brains. Acta Neuropathol. 106, 518-526. doi: 10.1007/s00401-003-0766-2

Imperatore, R., Palomba, L., and Cristino, L. (2017). Role of Orexin-a in hypertension and obesity. Curr. Hypertens. Rep. 19:34. doi: 10.1007/s11906017-0729-y

Iwata, A., Miura, S., Kanazawa, I., Sawada, M., and Nukina, N. (2001). alphaSynuclein forms a complex with transcription factor Elk-1. J. Neurochem. 77, 239-252. doi: 10.1046/j.1471-4159.2001.t01-1-00232.x

Jankovic, J., and Aguilar, G. (2008). Current approaches to the treatment of Parkinson's disease. Neuropsychiatr. Dis. Treat. 4, 743-757. doi: 10.2147/NDT. S2006

Kachroo, A., and Schwarzschild, M. A. (2012). Adenosine A2A receptor gene disruption protects in an $\alpha$-synuclein model of Parkinson's disease. Ann. Neurol. 71, 278-282. doi: 10.1002/ana.22630

Karamohamed, S., DeStefano, A. L., Wilk, J. B., Shoemaker, C. M., Golbe, L. I., Mark, M. H., et al. (2003). A haplotype at the PARK3 locus influences onset age for Parkinson's disease: the GenePD study. Neurology 61, 1557-1561. doi: 10.1212/01.WNL.0000095966.99430.F4

Karimi-Moghadam, A., Charsouei, S., Bell, B., and Jabalameli, M. R. (2018). Parkinson disease from mendelian forms to genetic susceptibility: new molecular insights into the neurodegeneration process. Cell. Mol. Neurobiol. 38, 1153-1178. doi: 10.1007/s10571-018-0587-4

Kikuchi, A., Takeda, A., Onodera, H., Kimpara, T., Hisanaga, K., Sato, N., et al. (2002). Systemic increase of oxidative nucleic acid damage in Parkinson's disease and multiple system atrophy. Neurobiol. Dis. 9, 244-248. doi: 10.1006/ nbdi.2002.0466

Kikuchi, Y., Yasuhara, T., Agari, T., Kondo, A., Kuramoto, S., Kameda, M., et al. (2011). Urinary 8-OHdG elevations in a partial lesion rat model of Parkinson's disease correlate with behavioral symptoms and nigrostriatal dopaminergic depletion. J. Cell. Physiol. 226, 1390-1398. doi: 10.1002/jcp. 22467

Kitada, T., Asakawa, S., Hattori, N., Matsumine, H., Yamamura, Y., Minoshima, S., et al. (1988). Mutations in the parkin gene cause autosomal recessive juvenile parkinsonism. Nature 392, 605-608. doi: 10.1038/33416

Koroglu, C., Baysal, L., Cetinkaya, M., Karasoy, H., and Tolun, A. (2013). DNAJC6 is responsible for juvenile parkinsonism with phenotypic variability. Parkinsonism Relat. Disord. 19, 320-324. doi: 10.1016/j.parkreldis.2012.11.006 
Krebs, C. E., Karkheiran, S., Powell, J. C., Cao, M., Makarov, V., Darvish, H., et al. (2013). The Sac1 domain of SYNJ1 identified mutated in a family with early-onset progressive parkinsonism with generalized seizures. Hum. Mutat. 34, 1200-1207. doi: 10.1002/humu.22372

Langston, J. W. (1996). The etiology of Parkinson's disease with emphasis on the MPTP story. Neurology 47, 153-160. doi: 10.1212/WNL.47.6_Suppl_3.153S

Lautier, C., Goldwurm, S., Durr, A., Giovannone, B., Tsiaras, W. G., and Pezzoli, G. (2008). Mutations in the GIGYF2 (TNRC15) gene at the PARK11 locus in familial Parkinson disease. Am. J. Hum. Genet. 82, 822-833. doi: 10.1016/j.ajhg. 2008.01.015

Lauretani, F., Saginario, A., Ceda, G. P., Galuppo, L., Ruffini, L., Nardelli, A., et al. (2014). Treatment of the motor and non-motor symptoms in Parkinson's disease according to cluster symptoms presentation. Curr. Drug Targets 15, 943-947.

Le, W., Xu, P., Jankovic, J., Jiang, H., Appel, S. H., Smith, R. G., et al. (2003). Mutations in NR4A2 associated with familial Parkinson disease. Nat. Genet. 33, 85-89. doi: $10.1038 /$ ng 1066

Lee, H., Baek, S. M., Ho, D., Suk, J., Cho, E., and Lee, S. (2011). Dopamine promotes formation and secretion of non-fibrillar alpha-synuclein oligomers. Exp. Mol. Med. 43, 216-222. doi: 10.3858/emm.2011.43.4.026

Leroy, E., Boyer, R., Auburger, G., Leube, B., Ulm, G., Mezey, E., et al. (1998). The ubiquitin pathway in Parkinson's disease. Nature 395, 451-452. doi: 10.1038/ 26652

Levin, J., Schmidt, F., Boehm, C., Prix, C., Bötzel, K., Ryazanov, S., et al. (2014). The oligomer modulator anle138b inhibits disease progression in a Parkinson mouse model even with treatment started after disease onset. Acta Neuropathol. 127, 779-780. doi: 10.1007/s00401-014$1265-3$

LeWitt, P. A., Rezai, A. R., Leehey, M. A., Ojemann, S. G., Flaherty, A. W., Eskandar, E. N., et al. (2011). AAV2-GAD gene therapy for advanced Parkinson's disease: a double-blind, sham-surgery controlled, randomised trial. Lancet Neurol. 10, 309-319. doi: 10.1016/S1474-4422(11)70039-4

Li, D. H., Wang, J., Mao, C. J., Hu, W. D., Xiao, L., Yang, Y. P., et al. (2011). Association of PARK 16 polymorphisms with Parkinson's disease in Han population of Suzhou. Zhonghua Yi Xue Za Zhi 91, 296-300. doi: 10.1016/ S1474-4422(11)70039-4

Li, Q. X., Mok, S. S., Laughton, K. M., McLean, C. A., Cappai, R., Masters, C. L., et al. (2007). Plasma alpha-synuclein is decreased in subjects with Parkinson's disease. Exp. Neurol. 204, 583-588. doi: 10.1016/j.expneurol.2006. 12.006

Liddle, R. A. (2018). Parkinson's disease from the gut. Brain Res. 1693(Pt B), 201-206. doi: 10.1016/j.brainres.2018.01.010

Lin, C.-H., Chen, M.-L., Chen, G. S., Tai, C.-H., and Wu, R.-M. (2011). Novel variant Pro143Ala in HTRA2 contributes to Parkinson's disease by inducing hyperphosphorylation of HTRA2 protein in mitochondria. Hum. Genet. 130, 817-827. doi: 10.1007/s00439-011-1041-6

Lin, K. J., Weng, Y. H., Hsieh, C. J., Lin, W. Y., Wey, S. P., Kung, M. P., et al. (2013). Brain imaging of vesicular monoamine transporter type 2 in healthy aging subjects by 18F-FP-(+)-DTBZ PET. PLoS One 8:e75952. doi: 10.1371/ journal.pone.0075952

Lin, L. F., Doherty, D. H., Lile, J. D., Bektesh, S., and Collins, F. (1993). GDNF: a glial cell line-derived neurotrophic factor for midbrain dopaminergic neurons. Science 260, 1130-1132. doi: 10.1126/science.8493557

Lodish, H., Berk, A., Matsudaira, P., Kaiser, C. A., Krieger, M., Scott, M. P., et al. (2004). in Molecular Cell Biology, 5th Edn, ed. J. Darnell (New York, NY: W.H. Freeman and CO), 66-72.

Luk, K. C., Kehm, V., Carroll, J., Zhang, B., O’Brien, P., Trojanowski, J. Q., et al. (2012). Pathological $\alpha$-synuclein transmission initiates parkinson-like neurodegeneration in non-transgenic mice. Science 16, 949-953. doi: 10.1126/ science. 1227157

Mahami Oskouei, M., Hamidi, F., Talebi, M., Farhoudi, M., Taheraghdam, A. A., and Kazemi, T. (2016). The correlation between Toxoplasma gondii infection and Parkinson's disease: a case-control study. J. Parasit. Dis. 40, 872-876. doi: 10.1007/s12639-014-0595-3

Martins-Branco, D., Esteves, A. R., Santos, D., Arduino, D. M., Swerdlow, R. H., and Oliveira, C. R. (2012). Ubiquitin proteasome system in Parkinson's disease: a keeper or a witness? Exp. Neurol. 238, 89-99. doi: 10.1016/j.expneurol.2012. 08.008
Masuda-Suzukake, M., Nonaka, T., Hosokawa, M., Oikawa, T., Arai, T., Akiyama, H., et al. (2013). Prion-like spreading of pathological $\alpha$-synuclein in brain. Brain 136, 1128-1138. doi: 10.1093/brain/awt037

Matsumoto, L., Takuma, H., Tamaoka, A., Kurisaki, H., Date, H., Tsuji, S., et al. (2010). CpG demethylation enhances alpha-synuclein expression and affects the pathogenesis of Parkinson's disease. PLoS One 5:e15522. doi: 10.1371/journal. pone. 0015522

McKeith, I. G., Boeve, B. F., Dickson, D. W., Halliday, G., Taylor, J. P., Weintraub, D., et al. (2017). Diagnosis and management of dementia with Lewy bodies: fourth consensus report of the DLB consortium. Neurology 89, 88-100. doi: 10.1212/WNL.0000000000004058

McLean, P. J., Kawamata, H., Ribich, S., and Hyman, B. T. (2000). Membrane association and protein conformation of $\alpha$-synuclein in intact neurons. Effect of Parkinson's disease-linked mutations. J. Biol. Chem. 275, 8812-8816. doi: 10.1074/jbc.275.12.8812

Miman, O., Kusbeci, O. Y., Aktepe, O. C., and Cetinkaya, Z. (2010). The probable relation between Toxoplasma gondii and Parkinson's disease. Neurosci. Lett. 475, 129-131. doi: 10.1016/j.neulet.2010.03.057

Mittermeyer, G., Christine, C. W., Rosenbluth, K. H., Baker, S. L., Starr, P., Larson, P., et al. (2012). Long-term evaluation of a phase 1 study of AADC gene therapy for Parkinson's disease. Hum. Gene Ther. 23, 377-381. doi: 10.1089/ hum.2011.220

Mollenhauer, B., Locascio, J. J., Schulz-Schaeffer, W., Sixel-Döring, F., Trenkwalder, C., and Schlossmacher, M. G. (2011). $\alpha$-Synuclein and tau concentrations in cerebrospinal fluid of patients presenting with parkinsonism: a cohort study. Lancet Neurol. 10, 230-240. doi: 10.1016/S1474-4422(11)70014-X

Muramatsu, S., Fujimoto, K., Kato, S., Mizukami, H., Asari, S., Ikeguchi, K., et al. (2010). A phase I study of aromatic L-amino acid decarboxylase gene therapy for Parkinson's disease. Mol. Ther. 18, 1731-1735. doi: 10.1038/mt.2010.135

Nagai, Y., Ueno, S., Saeki, Y., Soga, F., Hirano, M., and Yanagihara, T. (1996). Decrease of the D3 dopamine receptor mRNA expression in lymphocytes from patients with Parkinson's disease. Neurology 46, 791-795. doi: 10.1212/WNL.46. 3.791

Niethammer, M., Feigin, A., and Eidelberg, D. (2012). Functional neuroimaging in Parkinson's disease. Cold Spring Harb. Perspect. Med. 2:a009274. doi: 10.1101/ cshperspect.a009274

Obeso, J. A., Rodríguez-Oroz, M. C., Benitez-Temino, B., Blesa, F. J., Guridi, J., Marin, C., et al. (2008). Functional organization of the basal ganglia: therapeutic implications for Parkinson's disease. Mov. Disord. 23, 548-559. doi: 10.1002/ mds. 22062

Oertel, W. H. (2017). Recent advances in treating Parkinson's disease. F1000Res. 6:260. doi: 10.12688/f1000research.10100.1

Oh, J. K., Choi, E. K., Song, I. U., Kim, J. S., and Chung, Y. A. (2015). Comparison of I-123 MIBG planar imaging and SPECT for the detection of decreased heart uptake in Parkinson disease. J. Neural Transm. (Vienna) 122, 1421-1427. doi: 10.1007/s00702-015-1409-1

Olanow, C. W., Kieburtz, K., Odin, P., Espay, A. J., Standaert, D. G., Fernandez, H. H., et al. (2014). Continuous intrajejunal infusion of levodopa-carbidopa intestinal gel for patients with advanced Parkinson's disease: a randomised, controlled, double-blind, double-dummy study. Lancet Neurol. 13, 141-149. doi: 10.1016/S1474-4422(13)70293-X

Paisan-Ruiz, C., Bhatia, K. P., Li, A., Hernandez, D., Davis, M., Wood, N. W., et al. (2009). Characterization of PLA2G6 as a locus for dystonia-parkinsonism. Ann. Neurol. 65, 19-23. doi: 10.1002/ana.21415

Perni, M., Galvagnion, C., Maltsev, A., Meisl, G., Müller, M. B., Challa, P. K., et al. (2017). A natural product inhibits the initiation of $\alpha$-synuclein aggregation and suppresses its toxicity. Proc. Natl. Acad. Sci. U.S.A. 114, E1009-E1017. doi: $10.1073 /$ pnas. 1610586114

Pirker, W., Asenbaum, S., Wenger, S., Kornhuber, J., Angelberger, P., Deecke, L., et al. (1997). Iodine-123-epidepride-SPECT: studies in Parkinson's disease, multiple system atrophy and Huntington's disease. J. Nucl. Med. 38, 1711-1717.

Plaha, P., Ben-Shlomo, Y., Patel, N. K., and Gill, S. S. (2006). Stimulation of the caudal zona incerta is superior to stimulation of the subthalamic nucleus in improving contralateral parkinsonism. Brain 129, 1732-1747. doi: 10.1093/ brain/awl127

Pulkes, T., Choubtum, L., Chitphuk, S., Thakkinstian, A., Pongpakdee, S., Kulkantrakorn, K., et al. (2014). Glucocerebrosidase mutations in Thai patients 
with Parkinson's disease. Parkinsonism Relat. Disord. 20, 986-991. doi: 10.1016/ j.parkreldis.2014.06.007

Ramirez, A., Heimbach, A., and Grundemann, J. (2006). Hereditary parkinsonism with dementia is caused by mutations in ATP13A2, encoding a lysosomal type 5 P-type ATPase. Nat. Genet. 38, 1184-1191. doi: 10.1038/ng1884

Rappold, P. M., and Tieu, K. (2010). Astrocytes and therapeutics for Parkinson's disease. Neurotherapeutics 7, 413-423. doi: 10.1016/j.nurt.2010.07.001

Reiche, W., Grundmann, M., and Huber, G. (1995). Dopamine (D2) receptor SPECT with 123I-iodobenzamide (IBZM) in diagnosis of Parkinson syndrome. Radiologie 35, 838-843.

Reichmann, H., Brandt, M. D., and Klingelhoefer, L. (2016). The nonmotor features of Parkinson's disease: pathophysiology and management advances. Curr. Opin. Neurol. 29, 467-473. doi: 10.1097/WCO.0000000000000348

Reiter, R. J. (1995). Oxidative processes and antioxidative defense mechanisms in the aging brain. FASEB J. 9, 526-533. doi: 10.1096/fasebj.9.7.7737461

Rinne, J., Ruottinen, H., Bergman, J., Haaparanta, M., Sonninen, P., and Solin, O. (1999). Usefulness of a dopamine transporter PET ligand $[18 \mathrm{~F}] \beta-\mathrm{CFT}$ in assessing disability in Parkinson's disease. J. Neurol. Neurosurg. Psychiatry 67, 737-741. doi: 10.1136/jnnp.67.6.737

Saeed, U., Compagnone, J., Aviv, R. I., Strafella, A. P., Black, S. E., Lang, A. E., et al. (2017). Imaging biomarkers in Parkinson's disease and Parkinsonian syndromes: current and emerging concepts. Transl. Neurodegener. 6:8. doi: 10.1186/s40035-017-0076-6

Samii, A., Nutt, J. G., and Ransom, B. R. (2004). Parkinson's disease. Lancet 363, 1783-1793. doi: 10.1016/S0140-6736(04)16305-8

Sasaki, T., Amano, T., Hashimoto, J., Itoh, Y., Muramatsu, K., Kubo, A., et al. (2003). [SPECT imaging using [123I]beta-CIT and [123I]IBF in extrapyramidal diseases]. No To Shinkei 55, 57-64.

Satake, W., Nakabayashi, Y., Mizuta, I., Hirota, Y., Ito, C., and Kubo, M. (2009). Genome-wide association study identifies common variants at four loci as genetic risk factors for Parkinson's disease. Nat. Genet. 41, 1303-1307. doi: $10.1038 /$ ng.485

Scriabine, A. (1999). "Discovery and development of major drugs currently in use," in The Pharmaceutical Innovation: Revolutionizing Human Health, ed. A. Scriabine (Philadelphia: Chemical Heritage Press), 222-223.

Seppi, K., Schocke, M. F., Esterhammer, R., Kremser, C., Brenneis, C., Mueller, J., et al. (2003). Diffusion-weighted imaging discriminates progressive supranuclear palsy from PD, but not from the parkinson variant of multiple system atrophy. Neurology 60, 922-927. doi: 10.1212/01.WNL.0000049911. 91657.9D

Seraji-Bozorgzad, N., Bao, F., George, E., Krstevska, S., Gorden, V., Chorostecki, J., et al. (2015). Longitudinal study of the substantia nigra in Parkinson disease: a high-field $1 \mathrm{H}-\mathrm{MR}$ spectroscopy imaging study. Mov. Disord. 30, 1400-1404. doi: $10.1002 / \mathrm{mds} .26323$

Shadrina, M. I., Slominsky, P. A., and Limborska, S. A. (2010). Chapter 6. Molecular Mechanisms of Pathogenesis of Parkinson's disease. Int. Rev. Cell Mol. Biol. 281, 229-266. doi: 10.1016/S1937-6448(10)81006-8

Shi, C.-h., Tang, B.-s., Wang, L., Lv, Z.-y., Wang, J., Luo, L.-z., et al. (2011). PLA2G6 gene mutation in autosomal recessive early-onset parkinsonism in a Chinese cohort. Neurology 77, 75-81. doi: 10.1212/WNL.0b013e318221acd3

Shigenaga, M., Gimeno, C. J., and Ames, B. N. (1989). Urinary 8-hydroxy-2'deoxyguanosine as a biomarker of in vivo oxidative DNA damage. Proc. Natl. Acad. Sci. U.S.A. 86, 9697-9701. doi: 10.1073/pnas.86.24.9697

Siderowf, A., Aarsland, D., Mollenhauer, B., Goldman, J. G., and Ravina, B. (2018). Biomarkers for cognitive impairment in Lewy body disorders: status and relevance for clinical trials. Mov. Disord. 33, 528-536. doi: 10.1002/mds. 27355

Simon, D. K., Simuni, T., Elm, J., Clark-Matott, J., Graebner, A. K., and Baker, L. (2015). Peripheral biomarkers of Parkinson's disease progression and Pioglitazone effects. J. Parkinsons Dis. 4, 731-736. doi: 10.3233/JPD-150666

Singleton, A. B., Farrer, M., Johnson, J., Singleton, A., Hague, S., Kachergus, J., et al. (2003). A-synuclein locus triplication causes Parkinson's disease. Science 302:841. doi: 10.1126/science. 1090278

Skoloudík, D., Jelínková, M., Blahuta, J., Cermák, P., Soukup, T., Bártová, P., et al. (2014). Transcranial sonography of the substantia nigra: digital image analysis. AJNR Am. J. Neuroradiol. 35, 2273-2278. doi: 10.3174/ajnr.A4049

Steiner, J. A., Quansah, E., and Brundin, P. (2018). The concept of alphasynuclein as a prion-like protein: ten years after. Cell Tissue Res. 373, 161-173. doi: $10.1007 /$ s00441-018-2814-1
Strauss, K. M., Martins, L. M., Plun-Favreau, H., Marx, F. P., Kautzmann, S., Berg, D., et al. (2005). Loss of function mutations in the gene encoding Omi/HtrA2 in Parkinson's disease. Hum. Mol. Genet. 14, 2099-2111. doi: $10.1093 / \mathrm{hmg} / \mathrm{ddi} 215$

Sui, Y. T., Bullock, K. M., Erickson, M. A., Zhang, J., and Banks, W. A. (2014). Alpha synuclein is transported into and out of the brain by the blood-brain barrier. Peptides 62, 197-202. doi: 10.1016/j.peptides.2014.09.018

Surgucheva, I., and Surguchov, A. (2008). Gamma-synuclein: cell-type-specific promoter activity and binding to transcription factors. J. Mol. Neurosci. 35, 267-271. doi: 10.1007/s12031-008-9074-6

Surguchov, A. (2015). Intracellular dynamics of synucleins: here, there and everywhere. Int. Rev. Cell Mol. Biol. 320, 103-169. doi: 10.1016/bs.ircmb.2015. 07.007

Surguchov, A., Surgucheva, I., Sharma, M., Sharma, R., and Singh V. (2017). Poreforming proteins as mediators of novel epigenetic mechanism of epilepsy. Front. Neurol. 8:3. doi: 10.3389/fneur.2017.00003

Swanson, C. R., Berlyand, Y., Xie, S. X., Alcalay, R. N., Chahine, L. M., and Chen-Plotkin, A. S. (2015). Plasma apolipoprotein A1 associates with age at onset and motor severity in early Parkinson's disease patients. Mov. Disord. 30, 1648-1656. doi: 10.1002/mds.26290

Takahashi, Y., Kanbayashi, T., Hoshikawa, M., Imanishi, A., Sagawa, Y., Tsutsui, K., et al. (2015). Relationship of orexin (hypocretin) system and astrocyte activation in Parkinson's disease with hypersomnolence. Sleep Biol. Rhythms 13, 252-260. doi: $10.1111 /$ sbr. 12112

Tan, E.-K., Lin, C.-H., Tai, C.-H., Tan, L. C., Chen, M.-L., and Li, R. (2009). Non-synonymous GIGYF2 variants in Parkinson's disease from two Asian populations. Hum. Genet. 126, 425-430. doi: 10.1007/s00439-0090678-x

Tell-Marti, G., Puig-Butille, J. A., Potrony, M., Badenas, C., Milà, M., and Malvehy, J. (2015). The MC1R melanoma risk variant p.R160W is associated with Parkinson disease. Ann. Neurol. 77, 889-894. doi: 10.1002/ana. 24373

Tong, J., Wilson, A. A., Boileau, I., Houle, S., and Kish, S. J. (2008). Dopamine modulating drugs influence striatal $(+)-[11 C]$ DTBZ binding in rats: VMAT2 binding is sensitive to changes in vesicular dopamine concentration. Synapse 62, 873-876. doi: 10.1002/syn.20573

Valente, E. M., Abou-Sleiman, P. M., Caputo, V., Muqit, M. M., Harvey, K., Gispert, S., et al. (2004). Hereditary early-onset Parkinson's disease caused by mutations in PINK1. Science 304, 1158-1160. doi: 10.1126/science.1096284

van der Zee, S., Vermeiren, Y., Fransen, E., Van Dam, D., Aerts, T., Gerritsen, M. J., et al. (2018). Monoaminergic markers across the cognitive spectrum of Lewy body disease. J. Parkinsons Dis. 8, 71-84. doi: 10.3233/JPD-171228

van Duijn, C. M., Dekker, M. C., Bonifati, V., Galjaard, R. J., HouwingDuistermaat, J. J., Snijders, P. J., et al. (2001). Park7, a novel locus for autosomal recessive early-onset parkinsonism, on chromosome 1p36. Am. J. Hum. Genet. 69, 629-634. doi: 10.1086/322996

Venda, L. L., Cragg, S. J., Buchman, V. L., and Wade-Martins, R. (2010). $\alpha$-Synuclein and dopamine at the crossroads of Parkinson's disease. Trends Neurosci. 33, 559-568. doi: 10.1016/j.tins.2010.09.004

Vermeiren, Y., and De Deyn, P. P. (2017). Targeting the norepinephrinergic system in Parkinson's disease and related disorders: the locus coeruleus story. Neurochem. Int. 102, 22-32. doi: 10.1016/j.neuint.2016.11.009

Vilariño-Güell, C., Rajput, A., Milnerwood, A. J., Shah, B., Szu-Tu, C., Trinh, J., et al. (2014). DNAJC13 mutations in Parkinson disease. Hum. Mol. Genet. 23, 1794-1801. doi: 10.1093/hmg/ddt570

Vilariño-Güell, C., Wider, C., Ross, O. A., Dachsel, J. C., Kachergus, J. M., and Lincoln, S. J. (2011). VPS35 mutations in Parkinson disease. Am. J. Hum. Genet. 89, 162-167. doi: 10.1016/j.ajhg.2011.06.001

Vitali, C., Wellington, C. L., and Calabresi, L. (2014). HDL and cholesterol handling in the brain. Cardiovasc. Res. 103, 405-413. doi: 10.1093/cvr/cvu148

Vitali, M. C. T., Barreto-Sanz, M. A., Correia, B. R. S., Bell, R., Widnall, C., Perez, L. T., et al. (2018). miRNA-based signatures in cerebrospinal fluid as potential diagnostic tools for early stage Parkinson's disease. Oncotarget 9, 17455-17465. doi: 10.18632/oncotarget.24736

Wang, E. S., Sun, Y., Guo, J. G., Gao, X., Hu, J. W., Zhou, L., et al. (2010). Tetranectin and apolipoprotein A-I in cerebrospinal fluid as potential biomarkers for Parkinson's disease. Acta Neurol. Scand. 122, 350-359. doi: 10.1111/j.1600-0404.2009.01318.x 
Wang, L., Zhang, Q., Li, H., and Zhang, H. (2012). SPECT molecular imaging in Parkinson's disease. J. Biomed. Biotechnol. 2012;412486. doi: 10.1155/2012/ 412486

Watanabe, M., Maemura, K., Kanbara, K., Tamayama, T., and Hayasaki, H. (2002). GABA and GABA receptors in the central nervous system and other organs. Int. Rev. Cytol. 213, 1-47. doi: 10.1016/S0074-7696(02) 13011-7

Wienecke, M., Werth, E., Poryazova, R., Baumann-Vogel, H., Bassetti, C. L., Weller, M., et al. (2012). Progressive dopamine and hypocretin deficiencies in Parkinson's disease: is there an impact on sleep and wakefulness? J. Sleep Res. 21, 710-717. doi: 10.1111/j.1365-2869.2012.01027.x

Wu, Y. R., Lin, H. Y., Chen, C. M., Gwinn-Hardy, K., Ro, L. S., Wang, Y. C., et al. (2004). Genetic testing in spinocerebellar ataxia in Taiwan: expansions of trinucleotide repeats in SCA8 and SCA17 are associated with typical Parkinson's disease. Clin. Genet. 65, 209-214. doi: 10.1111/j.0009-9163.2004. 00213.x

Xu, L., Ma, B., Nussinov, R., and Thompson, D. (2017). Familial Mutations May Switch Conformational Preferences in $\alpha$-Synuclein Fibrils. ACS Chem. Neurosci. 8, 837-849. doi: 10.1021/acschemneuro.6b00406

Yang, Z., Wang, X., Yang, J., Sun, M., Wang, Y., and Wang, X. (2017). Aberrant CpG methylation mediates abnormal transcription of MAO-A. Neurotox. Res. 31, 334-347. doi: 10.1007/s12640-016-9686-5

Yonekura, Y., Saji, H., Iwasaki, Y., Tsuchida, T., Fukuyama, H., Shimatsu, A., et al. (1995). Initial clinical experiences with dopamine D2 receptor imaging by means of 2'-iodospiperone and single-photon emission computed tomography. Ann. Nucl. Med. 9, 131-136. doi: 10.1007/BF03165039
Yu, S., Li, X., Liu, G., Han, J., Zhang, C., Li, Y., et al. (2007). Extensive nuclear localization of $\alpha$-synuclein in normal rat brain neurons revealed by a novel monoclonal antibody. Neuroscience 145, 539-555. doi: 10.1016/j.neuroscience. 2006.12.028

Zeng, X. S., Geng, W. S., Jia, J. J., Chen, L., and Zhang, P. P. (2018). Cellular and molecular basis of neurodegeneration in Parkinson disease. Front. Aging Neurosci. 10:109. doi: 10.3389/fnagi.2018.00109

Zimprich, A., Biskup, S., Leitner, P., Lichtner, P., Farrer, M., Lincoln, S., et al. (2004). Mutations in LRRK2 cause autosomal-dominant parkinsonism with pleomorphic pathology. Neuron 44, 601-607. doi: 10.1016/j.neuron.2004.11. 005

Zucca, F. A., Basso, E., Cupaioli, F. A., Ferrari, E., Sulzer, D., Casella, L., et al. (2014). Neuromelanin of the human substantia nigra: an update. Neurotox. Res. 25, 13-23. doi: 10.1007/s12640-013-9435-y

Conflict of Interest Statement: The authors declare that the research was conducted in the absence of any commercial or financial relationships that could be construed as a potential conflict of interest.

Copyright (c) 2018 Emamzadeh and Surguchov. This is an open-access article distributed under the terms of the Creative Commons Attribution License (CC BY). The use, distribution or reproduction in other forums is permitted, provided the original author(s) and the copyright owner(s) are credited and that the original publication in this journal is cited, in accordance with accepted academic practice. No use, distribution or reproduction is permitted which does not comply with these terms. 